\title{
Using Taylorism to make work easier: A work procedure perspective
}

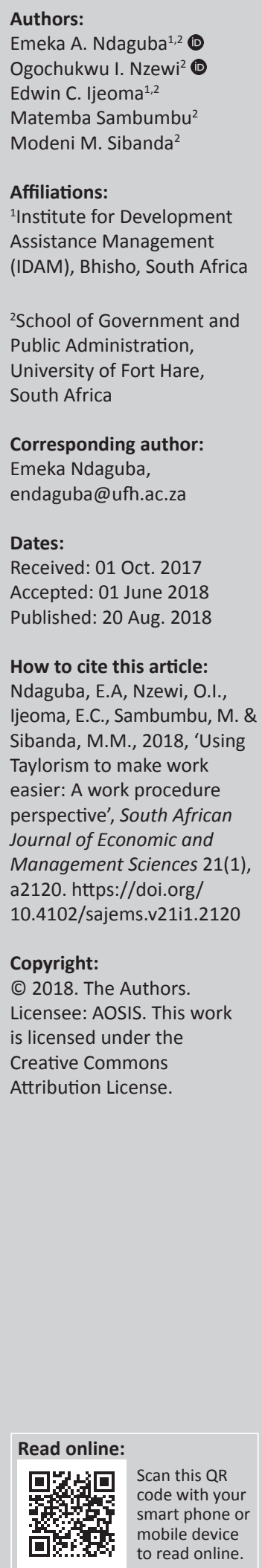

Background: Complexities generally are conundrums that inhibit efficiency and effectiveness in research and practice; one of the symptoms of this is nebulous obstruction to task completion in the workplace. Complexities in work procedures create complications in the application of procedures for completing tasks. Recent trends in the Auditor General's report have demonstrated the metastasising culture of non-compliance to work procedures in municipalities in South Africa. Research, as well as the audit outcomes for the Eastern Cape in particular, is a testament to this assertion. Therefore, there is no need to make work more complex.

Aim: To ascertain whether the application of Taylorism in the workplace could improve performance and to access the utilisation of work procedure in municipalities in the Eastern Cape.

Setting: This study was carried out using quantitative data collected from a District Municipality and its five local municipalities at the Transkei area of the Eastern Cape, South Africa.

Method: A survey completed by 593 municipality workers (junior workers) was collected and analysed using statistical methods and triangulation.

Results: Findings from the article reveals that work procedures in the organisation might be old and archaic. It may be relevant to workers who have little or no interference from externalities with regard to their job commitments. It recommends that those officials that perform routinised functions in municipalities should use a work procedure manual when completing their task. Based on the notion that work procedures engender compliance, increase outcome and output, increase productivity, save time, reduce stress and organisational friction or conflict in organisations.

Conclusion: It concludes that procedures that are comprehensible (simple), accessible (organically inputted and communicated) and accurate (effectively designed) will improve the daily functionality of lower echelon staff in the municipalities, especially those requiring little or no external influence on the completion of a task.

\section{Introduction}

Today's newspapers, magazines and articles show particular concern with non-compliance in work procedures that improve the performance of government functionality in South Africa as alluded to by the Auditor General South Africa (AGSA) reports 2010-2015. This assertion is reinforced by Scheepers (2012): '... negligence is a failure to comply with the standard of care that would be exercised in circumstances by a reasonable person'. The implication of Scheepers's assertion can be summarised as the effect of non-compliance on organisational success, in that non-compliance impacts negatively on staff performance, increases government wastage and results in suffering of the community and consequences that go far beyond the penalties and fines assigned to the individual or the department. Taylor's famous dictum is thus useful here: '... in the past, man has been first, in the future the System will be first' (Kanigel 1997; Rastegar 2004:78); this stresses the need for systems to operate optimally over individuals. Therefore, compliance is not mere rhetoric or mere formalities; rather, it is an avenue to rid a system of controversies and uncertainties and to improve a system rather than improving an individual.

The study gives a conceptual account of basic concepts and draws on essential principles guiding public administrators in South Africa. Using the fundamentals of Taylorism and the mechanistic approach, it summarises the finding of the study while stating some recommendations, which could improve organisational performance in line with the ideas and tenets of Taylorism in municipalities.

\section{Research objectives}

- To ascertain whether the application of Taylorism in the workplace could improve performance.

- To access the utilisation of work procedures in municipalities in the Eastern Cape. 


\section{Conceptual and theoretical framework}

\section{Taylorism}

Taylorism is an ideological shift towards production efficiency methodology that breaks every action, work, task or job into small particles or segments in order to complete them easily and without stress (Crown Online 2015). Taylorism, as developed by Frederick Taylor and other scholars of the scientific management school, introduced and popularised the concept to the field of management in the early 20th century. Taylorism has six main objectives:

- To achieve maximum job fragmentation.

- To minimise skill requirements and job learning times.

- To separate the execution of work from work planning.

- To separate direct labour from indirect labour.

- To replace rule-of-thumb productivity estimates with precise measurements.

- To make possible the payment-by-result method of wage determination.

It ultimately introduces time and motion study (Gilbreth \& Gilbreth 1973) for optimum job performance, cost accounting and tool and workstation design, and create baselines that are useful when evaluating future procedures, changes and resources (Business Directory 2015; Harper \& Mousa 2015).

\section{Work procedure}

In every governmental agency and department difficult work is broken into smaller tasks to increase efficiency and productivity. Division of such tasks enables the agency or department to function effectively (see the principles of division of labour by Karl Marx) by organising individuals and groups of employees to accomplish a task that only one person would have not been able to complete (the reason for public administration is to roll a stone that neither could roll alone) (Mundel \& Danner 1994; Ndaguba 2014:18). Work procedure can thus also be seen as a planned activity, involving mental and physical effort established as an official way of achieving an action or line of actions in a systematic way (Reid 2012). The main purpose for the utilisation of work procedure can be understood in these five cardinal points of view: it enables systematic completion of a task by:

- emphasising task specificity which leads to specialisation of a task

- ensuring that tasks are completed with less risk and stress; this is based on the wisdom

- that individual burnout leads to lowered productivity in organisations

- reducing repetition and idleness in the workplace

- reducing friction in task completion

- preventing organisational chaos and conflict (Crown Online 2015; Volunteer Canada 2001).

\section{Work structure}

All work is structured, tailored to a certain goal. Hence, the work structure of an organisation determines what the organisation intends to achieve and the means through which such is achieved. In other words, it determines the vision of the organisation and the mission through which such visions are achieved. Therefore, there is a need to take cognisance of the structure of an organisation, because the structure determines to some or a large extent the procedures in the fulfilment of organisational tasks. Therefore, according to Allen (n.d.), work structure is a step-by-step method that identifies dysfunctional aspects of workflow, procedures and systems, and realigns them to fit current realities to realise the goals of the organisation. The focal point of work structure is to improve both the technical side and compassionate side of the organisation (Prabhu 2010). However, Connor (n.d.) argues that work structure must not be merely limited to mapping out an organisation's total structure. Like Prabhu (2010), Connor argues that other aspects, such as functions, processes and strategies, as well as how these strategies, functions and processes are coordinated and harmonised, are necessary to achieve the overall objective of the organisation (Connor n.d.:1).

\section{Literature review}

\section{Mechanistic and classical organisational theories}

Work structure or design in the mechanistic realm is characterised by job functions which are 'broken-down into specialist tasks that were "precisely defined"' (Burns 1963:103; Connor n.d.:5). This model adopts the form of 'rigidity' because of the relatively stable business environment conditions in which it functions (Shafritz et al. 2011). Its major attributes include high rigidity, high levels of formalisation, low adaptive capabilities, high centralisation, high stratification, low complexity, high productivity and efficiency and low job satisfaction (Lunenburg 2012:4). See Figure 1 for more clarification of work procedure design.

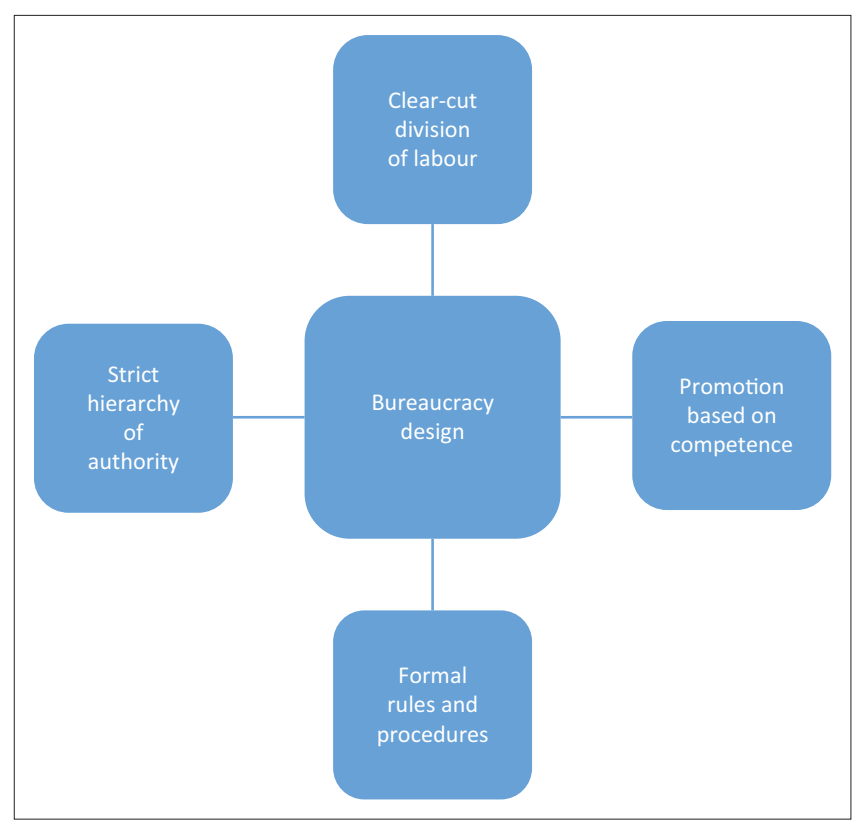

Source: McCuddy, M.K., n.d., Management, Canadian edition, John Wiley \& Sons, Ontario FIGURE 1: Bureaucratic organisational design. 
Thus, the conditions for organisational success in the mechanistic approach include:

- The overall goal of the organisation consists of tasks that can be divided into subtasks.

- Each task is simple enough that expertise for planning its execution is concentrated at higher levels.

- Valid measures of individual performance can be obtained.

- Employees respond to the monetary rewards for improved performance.

- Authority of managers is accepted as legitimate (Robey 1991).

These conditions were first set out in The principles of scientific management by Frederick Taylor in 1911, but still remain relevant.

\section{Taylorism}

In 1911 Taylor published his book on The principles of scientific management, in which he spelt out the process of scientifically studying work to improve workers' efficiency (Shafritz et al. 2015:68). The fundamental principle underlying Taylor's theory shaped the notion of organisational performance, organisational compliance and efficiency theory in the 20th century and beyond. Taylor's notion of work dealt significantly with, '... task specialization, assembly line production practices, job analysis, work design, incentive schemes, person-job fit, and production quotas and control' (Giannantonio \& HurleyHanson 2011:7; Rahman 2012:33). Taylor's argument was that work procedures should be characterised by job functions, which are 'broken-down into specialist tasks that were "precisely defined"' (Ndaguba 2014). There was a clear separation from employee to final completion of a product in that every employee was meant to focus on a little aspect of the production line (Eyre 2015), thereby gaining expertise as a result of routinisation of functions and tasks. Of note was that employees' performance was measured based on the number of tasks successfully completed (this notion has some similarities with the balance scorecard in monitoring and evaluation). However, employees completed their tasks with little or no knowledge as to the overall output of the product (Connor n.d.:5; Ndaguba 2014). This was one of the pitfalls of Taylorism, along with the notion that it sees employees as a $\operatorname{cog}$ in the wheel. However, one of the essential features of Taylorism is the close supervision of junior employees in task completion and, more so, the idea that only those who understand certain functions are meant to occupy such positions (square peg in square hole) (Burns 1963:103).

Taylorism has four underpinning principles, namely: to find the one 'best way' to perform each task, to carefully match each worker to each task, to closely supervise workers, and use reward and punishment as motivators, and finally to manage, plan and control (Walonick 1993).

These principles were seen in the early 20th century as being the only way through which employee performance could be measured accurately and the means through which productivity and efficiency could be improved. Although the notion of Taylorism was promulgated by an engineer, a core scientist, its ideas still remain relevant. Considering the nature of transdisciplinary research in social sciences and public administration, it would be misleading for one to disassociate Taylorism from understanding efficiency in the municipal system.

\section{Research methodology The research instrument}

Research design is the master plan or the logic of any inquiry. It gives an understanding of how research is conducted by demonstrating the structure and research strategy. This study employs a quantitative method in collecting its data for the work procedure design in municipal organisation. The questionnaire was sampled amongst junior workers at the district municipality and its surrounding five local municipalities.

\section{Research method}

The most popular classification of research methods is qualitative and quantitative. At one level, qualitative and quantitative may refer to distinctions between the nature of knowledge and the researcher's world view or the ultimate aim of the research. On another level, the terms refer to the way in which data are collected and analysed, and the type of generalisations and representations derived from such data (Brysman \& Burgess 1999:45). This study adopts a quantitative technique for gathering data. It uses a survey questionnaire while using cross-tabulation and regression to determine the strength of the relationship between variables.

This article used a descriptive research design. A quantitative empirical research approach was adopted, distributing selfadministered questionnaires with the assistance of 12 students in all 5 local municipalities (King Sabata Dalindyebo, Nyandeni, Ngquza Hill, Port St John's and Mhlontlo local municipality) and the district municipalities in 2014. Over 1200 questionnaires were distributed and 754 were returned. From this 754, 593 were correctly completed by junior employees. In selecting the respondents for this study, the purposive sampling method was utilised for the simple fact that we needed junior employees.

\section{Measuring instrument}

In this article, the Likert scale developed by Rensis Likert (1932) was favoured as the instrument for data collection. This instrument gives a wide range of answers to the respondent, in other to have a fair view as to how work is carried out in the municipality. The Likert scale gives range of choices of level of agreement with each option: 'every time' (100\%), 'frequently' (70\% - 90\%), 'sometimes' (50\% $60 \%)$, 'rarely' $(10 \%-30 \%)$ and 'never'. There are no right or wrong answers, since the idea is to procure the perceptions of the employees. 
The questionnaires for the study were self-administered; guidance was given by the researcher where necessary. Interpretation was also facilitated by the researchers who are native speakers of isiXhosa. The study used an identical and standardised questionnaire for every respondent. The Likert scale questionnaire type was used to elicit a broad spectrum of perspectives of junior employees in these municipalities.

\section{Data collection techniques}

There are two major sources of data collection techniques: primary and secondary data collection techniques. While primary data collection was done through surveys, secondary data were gathered using the desktop approach.

\section{Rationality for the choice of data collection technique}

This article adopted the primary technique of data collection on the basis that the topic is new to the municipality and to avoid speculations or assumptions about the state of affairs in the municipalities with regard to work procedure and work procedure design, and the usability of these procedures in the municipalities. Therefore, the best way forward to ascertain this was to use a survey questionnaire, and thereafter benchmark work procedure in the municipality by testing awareness, utilisation, attitude, type and design of work procedure in the municipalities.

\section{Sampling methods}

Sampling simply means selecting participants who best yield knowledge without bias. Having that in mind, sampling refers to the statistical process of selecting and studying the characteristics of a relatively smaller number of items from a relatively larger population of such items in order to make statistical inference about the characteristics of the entire population. Thus, empirical (quantitative) analyses tend to establish results that can be generalised to a larger set beyond the sample studied. The population of a study can either be homogeneous (if all members are identical, e.g. line management at Port St. Johns) or heterogeneous (if all members of the population are different from one another, e.g. assistant managers, managers, supervisors and other top officials). The essence of sampling is to get a sample (a subset of the population).

There are two broad types of sampling design open to scholars in social sciences: non-probability sampling techniques and probability sampling techniques. For this study the nonprobability technique is favoured, because senior managers have no chance of being selected in this study.

Non-probability sampling is a sampling technique which in the samples are gathered in a process that does not give all the individuals in the population equal chances of being selected (Crossman n.d.).

It is a sampling technique that is used to select participants premised on their knowledge of the study. To derive a sample, the judgmental or purposive sampling technique was utilised to avoid the inclusion of senior management in the research. Judgmental sampling refers to techniques used by the researcher to choose participants for research with the aim of achieving the research objectives.

Analysis for this study was carried out using $\mathrm{R}$ and triangulation of existing literature and the data set generated.

A referral kind of questioning was used, in which we asked similar questions in different ways. That protects the researcher, the research team, the research respondent and the environment from misconduct. Thereafter, a letter from the research institution through the principal investigator was sent to the gatekeeper informing the municipality of the period for the study. The major information that was addressed in the letter included:

- the need and importance of the study

- reduction of chaos

- redundancy

- the opportunities that this study could create for engendering and promoting work procedure design in the municipality.

A consent form stipulating the rights and privileges of the respondents was circulated to all participants; it was also explained in isiXhosa for non-English speaking employees.

\section{Ethical consideration}

Ethical clearance application was made to the University of Fort Hare Research Ethics Committee (REC) for an ethical clearance certificate.

\section{Results \\ Description analysis}

\section{Study method, population and sample}

To ascertain whether or not the application of Taylorism has any impact on performance, the data analysed below will show a distribution at a glance. Therefore, cognisance at this point must be drawn to the understanding that respondents of this survey are officials of the municipalities under consideration, responsible for the day to day utilization of work procedure.

There are five categories for rating the application and utilisation of work procedure for performance enhancement which includes: (1) Never (2) Rarely (10\% - 30\%); (3) Sometimes $(31 \%-60 \%)$; (4) Frequently $(61 \%-90 \%)$; (5) Every time $(91 \%-100 \%)$; (6) NA.

Figure 2 in this paper outlines the distribution by municipalities that participated in this survey.

Two hundred questionnaires were distributed to all the local municipalities. However, 400 were circulated in the district area. This was principally the reason why the 


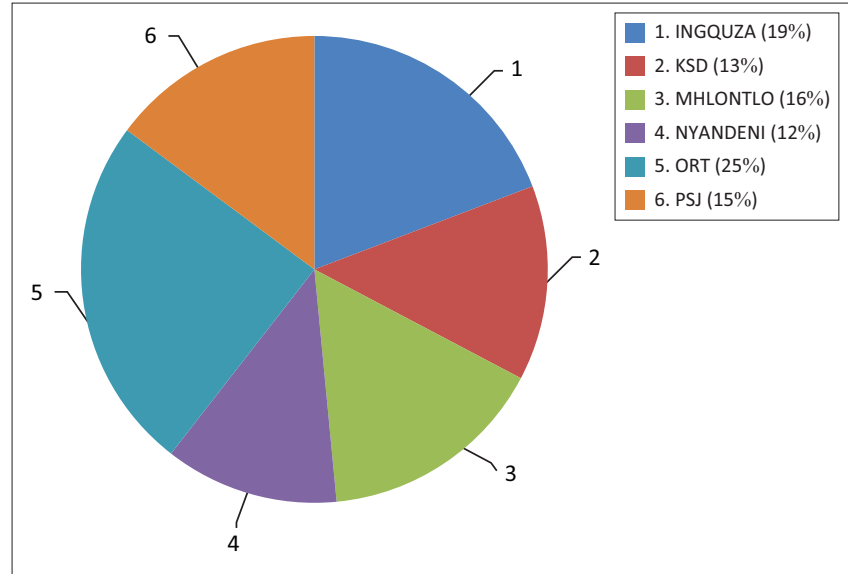

FIGURE 2: The distribution of participants by Municipality in percentage (\%).

TABLE 1: Distribution by qualification.

\begin{tabular}{lc}
\hline Qualification & Frequency \\
\hline Matric & 363 \\
Other (certificates programmes) & 230 \\
\hline Total & 593 \\
\hline
\end{tabular}

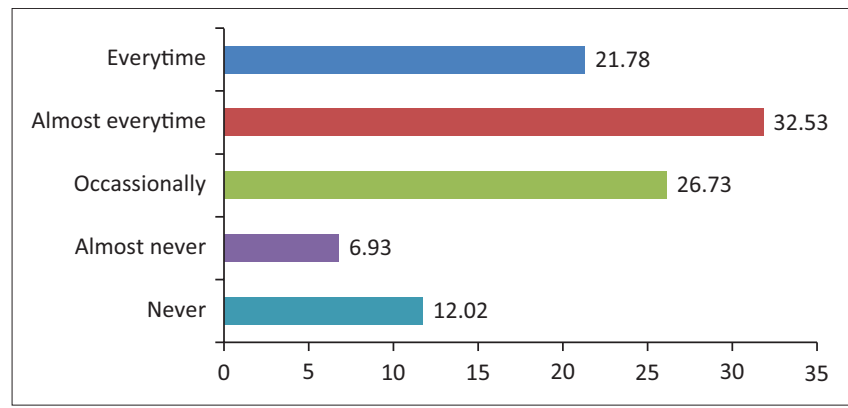

FIGURE 3: Compliance with accepted standards for completing a task in the municipality.

district municipalities had more employees than the local municipalities.

The reason for the use of Taylorism as a means for improving efficiency, productivity and performance in the municipalities is born of the idea that a higher percentage of junior workers in these municipalities have little educational qualification (see Table 1). This makes it presumably valid to argue that complexities in work procedure would complicate the assignments that need to be carried out, thereby depleting productivity, performance, outcomes and efficiency in delivering services to communities in a sustainable manner.

The next section of this article shows the results of the study. Bar charts were used to present the data, and beneath the presentation lies the analysis from which the finding from this article was synthesised with the literature and aim of the study (see figure 3).

Figure 3 demonstrates that about $22 \%$ of the respondents agreed that they comply to acceptable standards for completing task in the municipalities. In addition, $33 \%$ and $27 \%$ responded that they comply almost every time and occasionally. The study invariably shows that a total of $81 \%$ (which is a combination of

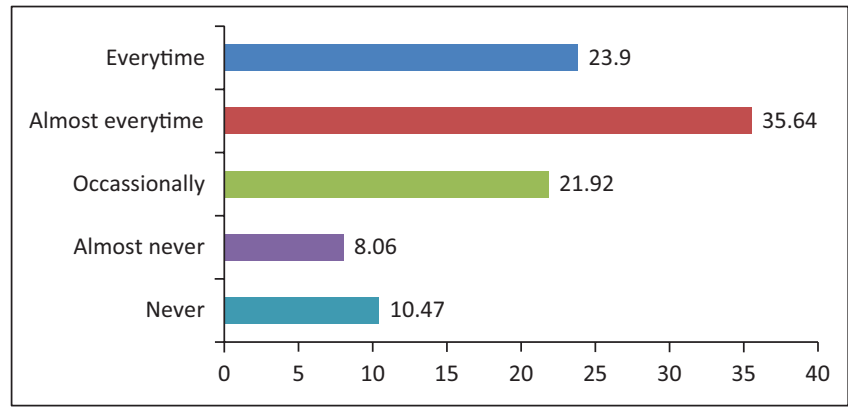

FIGURE 4: Compliance with the administrative reporting provisions of tasks.

'every time', 'almost every time' and 'occasionally') of respondents uses acceptable procedure documents for completing municipal functions in order to ensure efficiency and productivity. Productivity is seen by the Encyclopedia of management (Crown Online 2015), as the overall measure of the ability to produce a service or goods in relation to an outcome. More specifically, productivity is the measure of how resources of organisations are managed to accomplish the objectives of a task in a timely manner (see figure 4 for compliance).

Figure 4 shows that about $24 \%, 36 \%$ and $22 \%$ (representing 'every time', 'almost every time' and 'occasionally') comply with administrative provisions for municipal reporting as contained in several municipal guidelines, such as Municipal Strategic Self-Assessment (MuSSA) reports and Local Government Management Improvement Model (LGMIM). This infrequent use of work procedures in the municipalities explains the lack of productivity: with a paltry $24 \%$ using procedures to reduce friction and risk, one cannot wonder at the decay of service delivery and the failure of compliance of the financial statements of the municipalities (see AGSA reports 2011-2015, strike actions with regard to service delivery in the municipalities). However, while in Figure 3 $22 \%$ of participants meet the acceptable standard for completing a task, in Figure 4 where the utilisation of work procedures is analysed, $24 \%$ suddenly comply. This shows some discrepancies as to whether the employees of the municipalities are really aware of what constitutes proper work procedure, despite the two-day workshop offered to orientate the municipalities to the need for the use of work procedure and the importance of work procedure design for workplace improvement in municipalities.

The importance of adherence to work procedure cannot be over emphasised. As Osterberg (2005:487-497) and Goldberg et al. (2009:39) argued, the full benefit of a medication is achieved when a patient follows the prescribed regimen reasonably closely. As in the field of medicine, in most disciplines in the sciences there exists one best way of carrying out a procedure (hence Taylor's assertion); thus in this study we believed that in order for adherence to be achieved in the municipalities, there must exist one best way to complete a task, but not limited to the tenets of scientific management. Hence, there is a need to develop work procedure through consultation with staff, community workers, community organisations and non-governmental organisations (NGOs) in the communities in order to create 
the ideal municipality. The central piece of Taylorism is not just the establishment of one best way that reduces friction and chaos in organisations, while eliminating waste, undesired motion (processes) and time, which could result in saved costs and increased efficiency and productivity in the public service in South Africa (Locke 1982:15), but also setting a baseline for future engagements and the ability of public servants to be responsible for their actions (see figure 5).

Figure 5 shows that only $9.76 \%$ have never used established work procedures in completing their tasks. In contrast, $20.22 \%$ of the participants are certain that in completing every task (this is still in sync with the assertion of Figure 3), they adhere strictly to procedures that describe the role they play in achieving the overall functionality of the municipalities. Meanwhile, 61.23\% (consisting of 'almost every time' and 'occasionally') state that they use work procedure in the establishment of roles and in discharging their functions. This implies that most of the employees (junior) have a specific role. This is unarguably one of the resounding advocacies of Taylorism when he opined that each worker must be assigned a specific task (role) of a certain quality. This is reinforced by the work of Adam Smith on 'An inquiry into the nature and causes of the wealth of nations', where he opines that 'division of labour leads to specialization' (Adam Smith 1776). Gilbreth and Carey (1948), in the time and motion study Cheaper by the dozens, argue that the responsibilities and remote task of employees lead to the general organisational success in any sector (Gilbreth \& Carey 1948; Smith 1776). But where the lines of communication is compromised, much is left unanswered (see figure 6).

Figure 6 establishes that issues pertaining to the lines or channels of communication are paramount. Taking a scenario

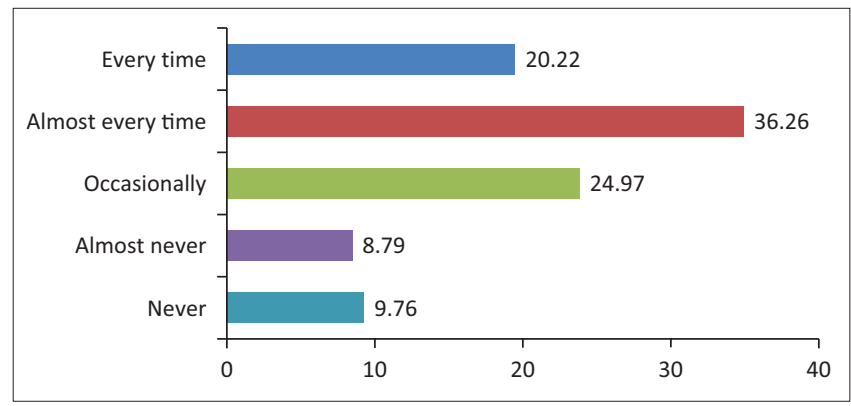

FIGURE 5: Establishment of organisational responsibility in municipal employees' roles in relation to completing a task.

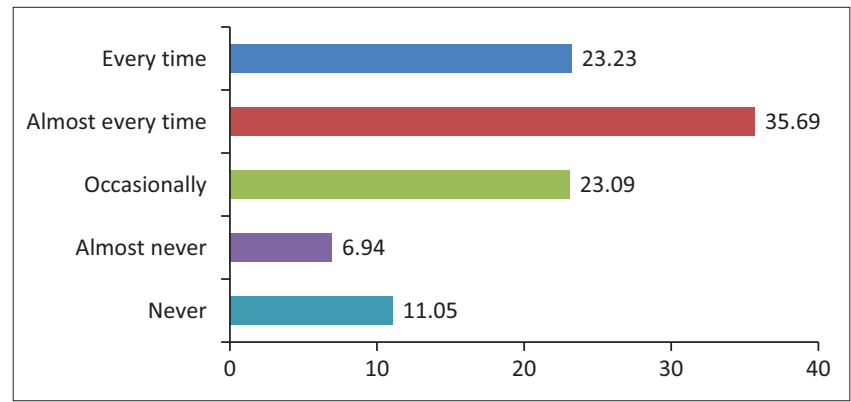

FIGURE 6: Establishing lines of communication in relation to the task. from a practical TV channel for instance: having one channel and sticking to that channel enables one to be familiar with every programme and the timing of each programme, which also gives the listener the opportunity to critique the channel where necessary, as compared to having several competing channels. Take another scenario, electronic mail: having a single email account for all correspondence in most cases is much preferable to having several email addresses. Hence, to reduce complexities in the workplace, it is also important that one established channel of communication is used, to avoid a situation or probability that employees do not receive the required communiqué at the appropriate time.

Thus Figure 6 shows that $23.38 \%$ of the participants adhere strictly to established communication lines in the municipalities. Meanwhile $36 \%$ of the participants argue that they use the established lines of communication 'almost every time'. $23.09 \%$ and $6.94 \%$ of the participants use established communication lines 'occasionally' and 'almost never'. A paltry $11.05 \%$ of the participant argue that they have never utilised the established lines of communication by the municipality in the performance of their duties in the public service. Although $11.05 \%$ might seem miniature, it could be the reason why the AGSA has always insisted that the municipalities have not met the mandatory standards for reporting (AGSA 2014). Also, and more importantly, if they have not been using the established means of communication, or not using them every time, what do they use? This is important and calls for further probing; hence, it will be wise to learn whether the means of communication used by other workers are more or less effective than the established lines of communication.

The need for communication is as important in an organisation as the need for the existence of that organisation. Where an organisation fails to communicate adequately and properly, it diminishes its relevance and existence. In this light we argue that every good report stems from good and effective communication. Good and effective lines of communication (verbal or written) are key to proper or optimal functionality and efficiency in any organisation (Johnson 2011). More so, communication on its own is a tool that cannot be ignored in everyday life, be it personal or public (Lorette 2010). In the public service, good communication (a prerequisite to transparency and accountability) is important to the daily operation of the service. Without good and effective (timely) communication, the internal and external structure of any organisation can face numerous challenges that can ultimately lead to its demise (VoiceGrid 2015). Three more scenarios illustrate the need for effective and good communication in organisations:

- Good communication is an essential tool in achieving productivity and maintaining strong working relationships at all levels in the public service.

- Municipalities and government agencies who invest time and energy into establishing clear lines of communication will rapidly build up levels of trust amongst employees, leading to increases in productivity, output and employee morale in general. 
- Poor communication in the workplace will inevitably lead to unmotivated staff that may begin to question their confidence, abilities and that of the organisation (Michael Page 2015) in completing tasks.

Therefore, it is paramount to establish clear channel of communication in relation to task completion in the municipalities, and also ensure that established legislative parameters are adhered to (see figure 7).

Figure 7 shows that $23 \%, 36 \%$ and $20 \%$ of participants (representing 'every time', 'almost every time' and 'occasionally') adhere to established legislative procedures to a high degree. However, $10.28 \%$ participants have never complied with established legislative provisions in completing their tasks. Legislative frameworks as exemplified in the Municipal Finance Management Act (Republic of South Africa 2007) speak to proper financial management and performance management, transparency, accountability, stewardship and good governance; the Employment Equity Act explains how recruitment occurs. Therefore, the limited number of those utilising this legislative framework could be one of the reasons why most of these municipalities have not been able to clinch a clean audit outcome from the AGSA report since 2011 and the reason for several interventions and multiple strike actions in 2014. It is important to note that to have an operational government at all levels, work procedures following legislation on finance and human resources must be taken seriously as they guide the way the budgets are formulated and presented, and stipulate clearly what the municipalities must strive to achieve, primarily in line with the procedural requirement of each municipality (see Figure 8).

For every task that is broken down there must be a procedure geared to fulfilling or performing or completing the task with

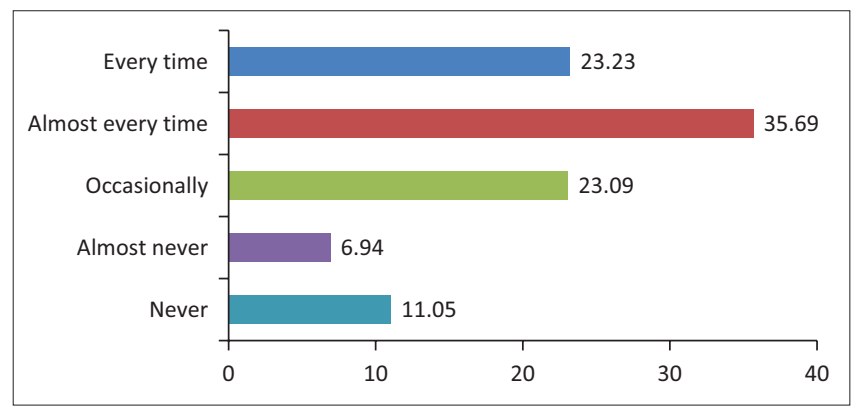

FIGURE 7: Compliance with established legislative parameters in completing a task.

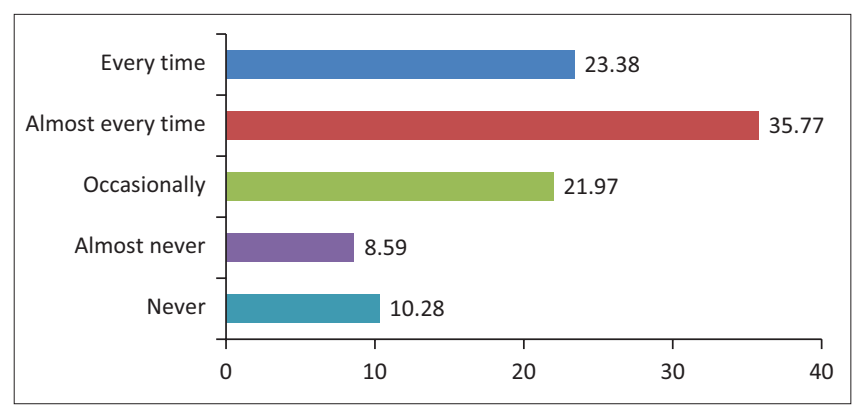

FIGURE 8: Compliance with procedural requirements of tasks. less effort and fewer resources (Taylor 1911). Taylorism is mainly about 'task specificity', ensuring that a task assigned to an employee is specific, and that the employee is trained to meet the requirements (see capability management) for fulfilling the task, is seen as one of its four principles (Taylor 1911). Figure 8 agrees totally that compliance with procedural requirements in fulfilling a task saves time and cost, with $23.47 \%$ of respondents saying that they comply every time with procedural requirements when doing their work. Meanwhile $36.13 \%$ and $20.63 \%$ confirm that they comply with procedural requirements in the completion of their tasks, but only to a certain degree. It is therefore important to understand what compliance with work procedures does to organisational efficiency: when compliance increases in a sector, does performance also increase or vice versa? In order to demonstrate whether or not compliance is an issue for municipalities, the presence or absence of a relationship needs to be established.

\section{Limitations of the current study}

One of the inadequacies of this study is that it did not take cognisance of all the negatives of Taylorism. We have used its positives in this argument because we strongly believe that Taylorism is an option for improving the efficiency of junior workers in municipalities in the area under review. The study is limited to junior workers in municipalities, so responses from management were not solicited. Nonetheless, this article nourishes the idea that certain approaches in Taylorism are vital in achieving organisational improvement, efficiency and productivity. This was the premise for using Taylorism to ensure the adoption and use of work procedures in municipalities in the Eastern Cape.

\section{Summary of findings}

The article demonstrated that:

- Taylorism has the potential for making work easier.

- Taylorism can improve performance and reduce friction and chaos.

- Taylorism is rejuvenating the public service in South Africa with over $80 \%$ of the participants agreeing that they use work procedures to complete tasks in the service in the municipalities.

- Compliance with work procedures is a prequel to performance improvement and efficiency in the sector for junior workers.

- Employees in the public service in South Africa use work procedures to establish processes in line with the roles and responsibilities for completing a task.

- Work procedures reduce organisational conflicts and chaos.

- Clear and properly written procedures enable workers to comprehend the direction and vision of the organisation.

- A well-coordinated work procedure enhances productivity in municipalities.

- About $90 \%$ of the participants have utilised the established lines of communication in relation to completing a task in the service, by implication complying with work procedure. 
- Established parameters or provision for the completion of tasks is important because it reduces fraud and increases productivity.

- Adherence to administrative and legislative procedures increases efficiency, influences higher performance and productivity in the public service in the municipalities.

Cross-referencing the four principles of Taylorism against the findings of the article shows that there exists a way of or pattern for doing things in the public service in South Africa, though it is not necessarily the one best way.

\section{Recommendation}

The study suggests that management of these municipalities must develop the 'one best way', which should be revisited frequently to ensure that functions are tied to the objectives of the municipality.

The study suggests that municipalities with large numbers of staff in the lower echelon, performing routine functions, requiring low complexity and technicality in completing a tasks or functions in the municipality, could find certain elements and tenets of Taylorism useful in improving the performance of these workers.

Finally, for employees in the lower echelon in municipalities in the Eastern Cape to work in concert with the vision of the municipality, tasks need to be broken down and precisely defined. This will enable managers to exact accountability from junior employees of these municipalities. The notion of good governance is premised in relation to compliance to standard, openness, effective communication on decisions reached, information on service delivery, transparency in government business and accountability in the appropriation of government properties; these are at the centre of the ideal of Taylorism. Therefore, a skillful application of the tenets of Taylorism would result in an improved performance that reduces organisational conflict, government wastage, improper cost and chaos, and engender task completion that invariably improves the outcomes and performance of municipalities in delivering services to locals on the one hand and achieving the AGSA outcomes on the other hand.

\section{Conclusion}

In conclusion, Taylorism is a call to compliance, a call to break down complex work processes, a call for higher productivity and efficiency. It is more useful and user friendly for employees of lower capabilities or lower qualification performing routine jobs. It is best in and suited to a stable environment with little or no external influence. A workplace such as the municipalities under review, having low complexity, low adaptive capacity or ability and routinised work processes and procedures, would harness significant growth if it were to stick to the principle of Taylorism (Lunenburg 2014:4; Shafritz et al 2015). The article found that the tenets of Taylorism are rejuvenating amongst less qualified staff members in the South African public service, especially with regard to junior workers. As seen in the results, the majority of employees use this method for completing tasks in these municipalities on a daily basis. However, worrisome is the nature of work procedure used in these municipalities, which might be derailing performance, effectiveness and efficiency. Hence, there is a need to revisit the work procedure as it is presently constituted and look for the right and best way for task completion in the 21st century, which is in tandem with the call for neo-Taylorism in the 21st century. The objectives of the article were realised, in that the results demonstrated that work procedure application in the workplace leads to the improvement of performance.

\section{Acknowledgments Competing interests}

The authors declare that they have no financial or personal relationships that may have inappropriately influenced them in writing this article.

\section{Authors' contributions}

E.A.N. was the primary writer of this paper, he was supervised by O.I.N., the leader of the study was E.O.C.I., M.S. and M.M.S. were very instrumental in data collection and analysis of the study.

\section{References}

Auditor-General South Africa, 2013, General report on the audit outcomes of local government MFMA, AGSA, Pretoria.

Auditor-General South Africa, 2014, General report on the audit outcomes of local government MFMA, AGSA, Pretoria.

Auditor-General South Africa, 2015, Audit terminology, viewed 12 July 2015, from https://www.agsa.co.za/Auditinformation/Auditterminology.aspx

Brysman, A. \& Burgues, R., 1999, 'Qualitative research', in B. Hollstein, B. (ed.), Qualitative approaches. Sage handbook of social network analysis, Sage, London.

Burns, T. \& Stalker, G., 1961, The management of innovation, Tavistock, London.

Burns, E.M., 1963, Western civilizations: Their history and culture, 6th edn., W.W. Norton and Company, New York.

Business Dictionary, 2015, Taylorism, viewed 12 July 2015, from http://www. businessdictionary.com/definition/Taylorism.html\#ixzz3fgrNEtgr

Connor, G., McFadden, M. \& McLean, I., 2012, 'Organisation design', in J. Stewart \& P. Rogers (eds.), Developing people and organisations, pp. 1-36, CIPD - Kogan Page, London.

Crown Online, 2015, Crown copyright with value added product status, viewed 09 July 2015, from http://www.knowledgetransfer.net/dictionary/ITIL/en/Procedure. htm

Eyre, E., 2015, Frederick Taylor and scientific management: Understanding Taylorism and early management theory, viewed 13 July 2015, from www.mindtools.com/ pages/article/newTMM_Taylor.htm

Giannantonio, C.M. \& Hurley-Hanson, A.E., 2011, 'Frederick Winslow Taylor: Reflections on the relevance of the principles of scientific management 100 years later', Journal of Business and Management 17(1), 7-10.

Gilbreth, F.B. \& Gilbreth, L., 1973, Fatigue study: The examination of humanity's greatest waste; a first step to motion study, Hive, Easton, PA.

Gilbreth, F.B. \& Carey, E.G. 1948, Cheaper by the dozen, Bantam Books, New York, NY.

Goldberg, E.L., Dekoven, M., Schabert, V.F., \& Coyle, A., 2009, 'Patient medication adherence: The forgotten aspect of biologics', Biotechnology Healthcare 6(2), 39-44.

Harper, S. \& Mousa, F.T., 2015, 'Time and motion studies', in R.W. Griffin (ed.), Management, Oxford University Press, Cambridge, MA.

Johnson, R., 2011, What are the benefits of effective communication in the workplace?, viewed 01 July 2015, from smallbusiness.chron.com/benefits-effectivecommunication-workplace-20198.html

Kanigel, R., 1997, The one best way: Frederick Winslow Taylor and the enigma of efficiency, Viking, New York, NY.

Likert, R. 1932, 'A technique for the measurement of attitudes', in R.S. Woodworth (ed.), Archives of psychology, University of New York, New York, NY. 
Locke, E.A., 1982, 'The ideas of Frederick W. Taylor: An evaluation', Academy of Management: The Academy of Management Review 7(1), 14-24.

Lorette, K., 2010, Importance of good communication in business, viewed 11 July 2015, from smallbusiness.chron.com/importance-good-communicationbusiness-1403.html

Lunenburg, F.C., 2012, 'Mechanistic-organic organizations - An axiomatic theory: Bureaucracy or professional norms', International Journal of Scholarly Academic Intellectual Diversity 14(1), 1-7.

Michaelpage, 2015, The importance of good communication, viewed 12 July 2015 from www.michaelpage.co.uk/employer-centre/development-and-retentionadvice/the-importance-of-good-communication

Mundel, M.E. \& Danner, D.L., 1994, Motion and time study: Improving productivity, Prentice Hall, Englewood Cliffs, NJ.

Ndaguba, E.A., 2014, 'Work procedure design in municipal government in Eastern Cape: A case study of Oliver Reginald Tambo District Municipality (ORTDM)', University of Fort Hare (mini-dissertation), University of Fort Hare Library.

Prabhu, J., 2010, Organisation theory and design, Viewed from http://www.slideshare. net/JayashreePrabhu/organisation-theory-design

Rastegar, D.A., 2004, 'Health care becomes an industry', Annals of Family Medicine 2(1), 79-83. https://doi.org/10.1370/afm.18

Reid, C., 2012, Processes, procedures, work instructions - What's the difference anyway?, viewed 20 June 2014, from http://www.theprocessninja.com/2012/05/
Republic of South Africa, 2007, Local Government: Municipal Finance Management Act, No. 56, Government Printer, Cape Town.

Robey, D., 1991, Designing organisations, Irwin, Boston, MA.

Osterberg, L. \& Blaschke, T., 2005, 'Drug therapy: Adherence to medication', The New England Journal of Medicine 353, 487-497.

Scheepers, J., 2012, 'Negligence - A ground for disciplinary action', in The South African Labour Guide, viewed 22 June 2018, from https://www.labourguide. co.za/most.../2031-negligence-a-ground-for-disciplinary-action

Shafritz, J.M. Ott, S.J. \& Jang, Y.S., 2011, Classics of organizational theory, 7th edn., Wadsworth, Belmont, CA.

Shafritz, J.M., Russell, E.M. \& Borick, C., 2015, Introducing public administration, 8th edn., Taylor and Francis, Philadelphia, PA.

Smith, A., 1776, The wealth of nations, William Strahan \& Thomas Cadell, London.

Taylor, F.W., 1911, The principle of scientific management, Cosimo Classics, New York.

VoiceGrid, 2015, Communication in a modern age, viewed 10 July 2015, from voicegrid.ie/testblog/68-communication-in-a-modern-age

Volunteer Canada, 2001, A matter of design: Job design theory and application to the voluntary sector, Volunteer Canada, Ottawa.

Walonick, D.S., 1993, Organizational theory and behavior, viewed 09 July 2015, from http://www.statpac.org/walonick/organizational-theory.htm 


\section{Appendix 1 \\ Questionnaire: Utilisation of organisational procedures}

This section deals with the use of organisational procedure with regard to compliance and efficiency.
Indicate appropriately (please select the applicable number in the table below):

- $1=(0-20)$ Never

- $2=(21-40)$ Almost never

- $3=(41-60)$ Sometimes

- $4=(61-80)$ Almost every time

- $5=(81-100)$ Every time

TABLE 1-A1: I use work procedures to...

Compliance

Find out the accepted standards needed for the task

Comply with the administrative reporting provisions of the task

Establish process roles and responsibilities in relation to the task

Establish lines of communication in relation to the task

Comply with established legislative parameters in the task

Comply with the procedural requirements of the task 